\title{
Integration of the supply system in design
}

\author{
Vera Akristiniy, ${ }^{1, *}$ \\ ${ }^{1}$ Moscow State University of Civil Engineering, Yaroslavskoe shosse, 26, Moscow, 129337, Russia
}

\begin{abstract}
The article discusses ways to obtain positive effects when integrating the supply system into the design during the implementation and completion of the investment-construction project. The use of the principles of centralization and decentralization with the distribution of the main functions of the parent and subsidiary construction organizations is proposed. The improving mechanism for the material and technical supply system is consolidated according to principles of planning, organization, and control. The stages of a supply system integration into the building design are proposed during the implementation of the investmentconstruction project. The proposed mechanism allows you to plan the work of the supply system during the construction period, reduce the time frame for the implementation of the investment-construction project and obtain savings in financial resources.
\end{abstract}

\section{Introduction}

Material and technical supply is one of the distribution and delivery forms of production means in the construction industry based on organizational ties and contracts between suppliers and consumers directly from manufacturers of building materials and machinery or through intermediaries. It largely determines the rhythm and effectiveness of construction production, having a direct impact on the effective use of the active part of the main production assets of contracting construction enterprises, reducing the net cost of commercial products and construction time, increasing labor productivity and many other indicators [1].

The process of material and technical supply should include operations to provide the construction site with objects and means of labor, in quantity and terms, corresponding to the documentation and the schedule of work. Violation of the schedule for the delivery of products regulated by the schedule may cause a failure to meet the deadlines for the delivery of intermediate or final finished products when performing subsequent types of work. In turn, failure to comply with the stated requirements for the quality, completeness, size, and dimensions of the supplied inventory leads to an increase in the cost of products due to possible disruption of work schedules, downtime, labor resources and penalties set by the construction owner [2]. Timely delivery of the required quality inventory, completeness and assortment can significantly reduce the cost of resources for the manufacture of products (delivery of work-performed volumes) and eliminate the risk of untimely commissioning of the building. Consequently, the efficiency of the production and

\footnotetext{
*Corresponding author: 7824666@mail.ru
} 
technical functions directly depends on the efficiency of the and material and technical supply service, not only in this area but also at all further stages of construction. The supply of production means is the most important component of the construction company in terms of material and technical supply management $[3,4]$.

The efficiency of the logistics and material and technical supply service shows that reducing the cost of supplying products as a result of optimizing procurement by $1 \%$ can increase the organization's profit by $12 \%$. In this regard, constant coordination of procurement activities isextremely important: correctly determine the size of the order and the necessary time for its receipt at the construction site, as well as take into account the expected changes in prices and the volume of output on the market $[5,7]$.

When implementing investment and construction projects, a construction organization faces the following problems [6]:

1. Disruption of the production schedule due to the untimely placement of the purchase application due to lack of control (participation) by the parent organization.

2. Due to the insufficiently detailed study of the need for inventory, the formation of unused residues that lose their operational characteristics over time.

3. The likelihood of abuse in procurement.

4. The narrow range of suppliers of material assets.

5. Loss of profit due to the isolation of units and the lack of study of the possibility of using unused material and inventory support facilities at construction sites of other units.

6. The lack of a tool for the development and implementation of innovative materials that can be more effective in terms of strength characteristics, production time, price, etc.

7. Lack of a tool for preliminary project development on the possibility of unhindered procurement of materials laid down by design organizations.

\section{The method of the supply system integration in the building design}

Identified types of distribution of the main functions for the development of a method for integrating the material and technical supply system into the design during the implementation of investment and construction projects. It is determined that in connection with the structural features of construction organizations, the logistics, and material and technical supply functions can be distributed between the parent organization and units or concentrated in one of them according to the principle of centralization and decentralization $[8,9]$. The main difference between these principles is that decentralization is characterized by the process of concentration of supply functions (demand planning, organization of procurement, control and coordination of work) in subsidiary organizations, and with centralization, similar processes occur in the parent organization [10].

Based on the data on the structure of the largest construction organizations in Russia, it was revealed that, regardless of the investment and construction project being implemented, most of the supply functions are concentrated directly in subsidiaries, the interaction between which is minimal [11,12].

A solution to these problems may be a system based on the centralization of procurement activities. A transformation mechanism is proposed through the separation of the demand planning function between departments and the parent organization (Fig. 1). 


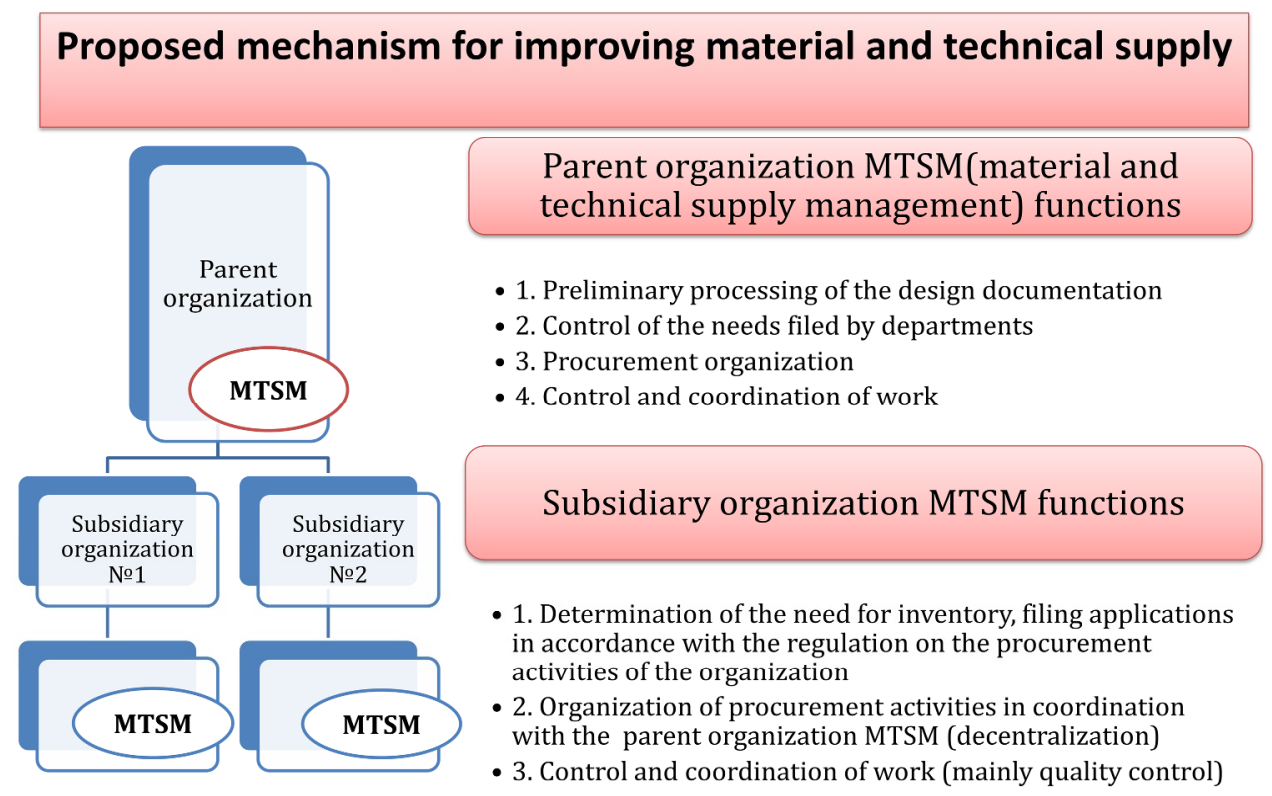

Fig. 1. The distribution of the material and technical supply functions in the parent and subsidiary organizations.

Using the proposed mechanism for improving material and technical supply, presented in Fig. 1, the following results can be obtained [13]:

1. Savings in the funds of the construction organization due to the wholesale purchase of identical material and technical values (discounts for large volumes, reduced logistics and procurement costs, etc.).

2. Stimulating competition between suppliers due to the volume of lots.

3. Simplification of the control procedure during the organization and conduct of tenders, procurements (lack of duplication of orders, exclusion of informal procurement procedures, increased control over the fulfillment by suppliers of contractual obligations, etc.)

4. The ability to hire employees with highly specialized knowledge (in the context of a certain nomenclature) to achieve the maximum economic effect from the procurement.

The proposed integration mechanism is based on the principles of the optimal ratio of decentralization and centralization during the fulfillment of material and technical supply in the process of implementing an investment construction project by a construction organization [14].

The functions of material and technical supply are divided between subsidiaries and the created management in the parent organization. It is especially worth noting that the supply will be present both in the parent organization and in the subsidiaries. They will work together to achieve the maximum result of the construction company.

The main task of the created department of material and technical supply management of the parent organization is to ensure the integration of the processes of placing orders preparation for inventory items into a single whole, the manufacture of semi-finished products, structures and their complete delivery to construction sites in accordance with the schedule of construction and installation works taking into account the stocks residuals available at the enterprise $[15,16]$.

The main advantage of such an organization of material and technical supply of construction production is that during the creation and development of management at a 
construction company all functions and departments of material and technical supply and equipment are concentrated in one place, which was previously dispersed between its individual divisions, departments, and services, which led to a loss of observability and controllability of the supply process.

If the general contractor implements this model of material and technical supply, the effect can be achieved due to the rationalization and optimization of logistics processes conducted by him. The proposed work plan of the material and technical supply management allows for better coordination of supplies, which is especially important when erecting large construction projects, with tight construction deadlines and cramped conditions [17].

As the main stages of material and technical supply during the implementation of the investment and construction project in the proposed optimizing scheme, we can distinguish (Fig. 2) $[15,18]$ :

1. Planning for procurement at the design documentation stage. At this stage, the material and technical supply management are considering project documentation on the possibility of an unhindered purchase of the materials laid down in the documentation. The implementation of this process is an innovation since often the contractor receives a project that has passed the examination, and any deviations from the decisions laid down in the project lead to the need to undergo a repeated examination, which threatens the company with a loss of time and finances [19].

2. Planning for procurement at the detailed design documentation stage. When organizing material and technical supply, it is recommended to separate the procurement authority of certain stock groups between the parent and subsidiary organizations.

3. The fulfillment of material and technical supply at the stage of «Organization». After receiving a justified demand from the subsidiaries MTSM, the application is processed by the responsible manager of the parent organization MTSM.

4. The fulfillment of material and technical supply at the stage of «Control».

\begin{tabular}{|l|l|l|l|l|l}
\hline Proposed mechanism for improving material and technical supply \\
Executive:
\end{tabular}

Fig. 2. The mechanism for improving the material and technical supply system.

A detailed structuring of the main stages of the supply system integration into the design during the implementation of the investment and construction project is presented in Fig. 3. 


\section{Proposed mechanism for improving material and technical supply}

\section{Functions}

- 1. 1. Preliminary processing of project documentation on the possibility of delivery of materials laid down by the design organization; the use of modern and effective materials; the use of more cost-effective materials, taking into account quality indicators, that is not lower than laid down in the design documentation

- 1.2. Initiation of the procedure for the reconciliation of materials in case of:

- the lack of them on the market;

- the use of more efficient materials;

- the use of more cost-effective materials, taking into account quality indicators, that is not lower than laid down in the design documentation;

- 1.3Monitoring the adjustment of project documentation and the inclusion of the proposed materials in the procurement plan

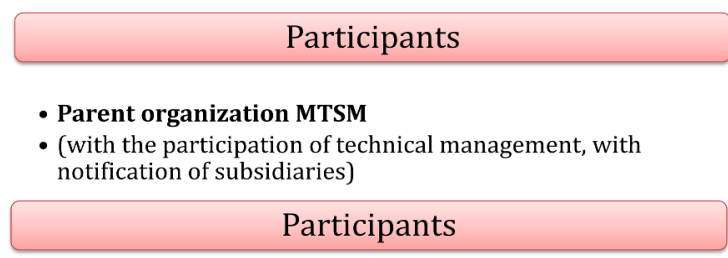

- Parent organization MTSM

- (with the participation of technical management, with notification of subsidiaries]

\section{Participants}

- Parent organization MTSM and subsidiary organizations MTSM

Fig. 3. Stages of the supply system integration into the design.

\section{Practical results}

The mechanism for integrating the material and technical supply system into the design was introduced during the implementation of the investment and construction project "Construction of the transport passage through the Kerch Strait", the architectural concept of which is presented in Fig. 4.

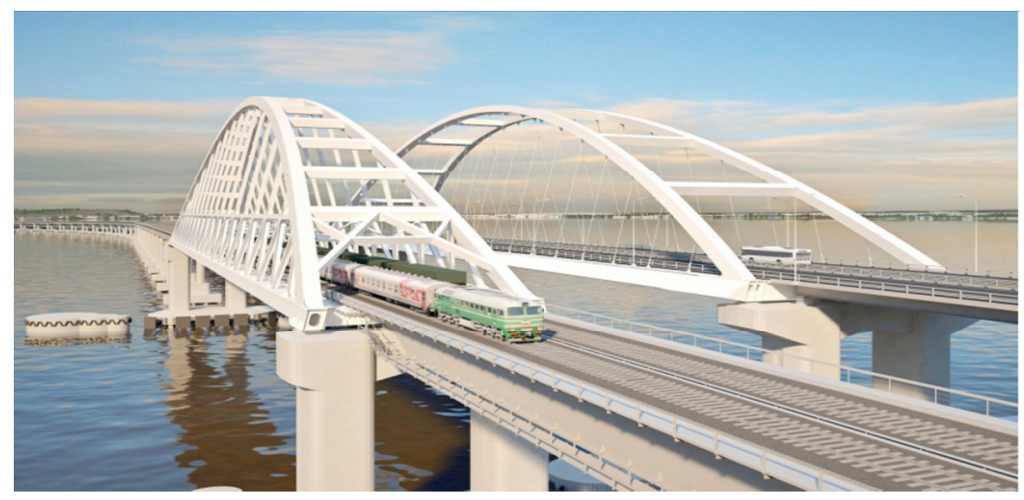

Fig. 4. The architectural concept of the object «Construction of the transport passage through the Kerch Strait».

To analyze the effectiveness, we consider the main results of changes in the redistribution of the MTSM functions between the parent and subsidiary organizations transfer of the main MTSM functions to the parent organization - based on the data of the implemented investment and construction project [15]:

- function «Planning at the design documentation stage»;

- function «Planning at the detailed design documentation stage»;

- function«Organizing»;

A. Function «Planning at the design documentation stage»; 
The main problem at this stage is the impossibility of purchasing the materials laid down in the project documentation in connection with the termination of their release. The disadvantages of the traditional scheme of material reconciliation in such cases will be as follows:

- loss of time, therefore, simple equipment and labor;

- loss of material resources in the event of a customer's failure to change the estimated cost.

This can be avoided by using an integrated circuit under consideration, in which the supply system will consider the project documents prior to the start of construction, indicating the problem points to be faced by the organization in the procurement of materials.

The following aspects can be presented as examples of the effectiveness of the applied mechanism. The selection of alternative options in the process of reconciling individual materials for the structural elements of the project (Fig. 5) is presented in Table 1 [15,21].
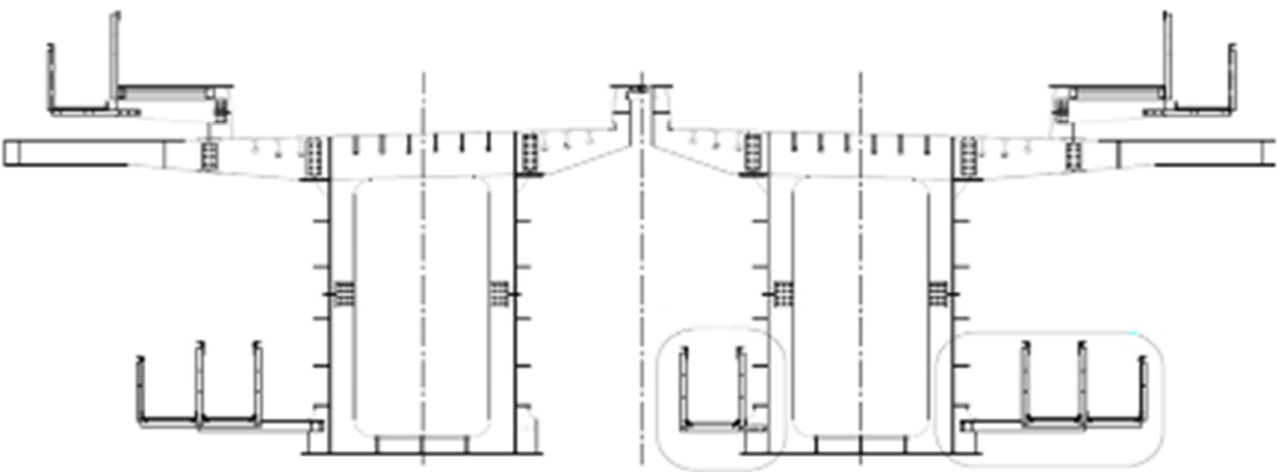

Fig. 5. Cross-section of the span of the railway bridge with dedicated nodes of service passages in the construction of which flooring is used.

Table 1. Selection of alternative options for a structural element according to the approved characteristics in the design documentation.

\begin{tabular}{|l|l|l|}
\hline \multicolumn{1}{|c|}{ Characteristic } & Units \\
\hline Visual image & & \\
\hline $\begin{array}{l}\text { Specific weight } \\
\text { structural elements }\end{array}$ & $\mathrm{kg} / \mathrm{m}^{2}$ & \\
\hline $\begin{array}{l}\text { The total specific } \\
\text { metal coating with } \\
\text { he additional } \\
\text { elements }\end{array}$ & $\mathrm{kg} / \mathrm{m}^{2}$ & 35
\end{tabular}




\begin{tabular}{|l|c|c|c|}
\hline $\begin{array}{l}\text { Performance and } \\
\text { installation work for } \\
1 \text { day }\end{array}$ & $\mathrm{m}^{2}$ & Upto 30 (welder-installer) & $\begin{array}{c}\text { Morethan 150 (auxiliary } \\
\text { worker) }\end{array}$ \\
\hline $\begin{array}{l}\text { Вид покрытия } \\
\text { поверхности }\end{array}$ & - & 40 microns (primer + coloring) & $\begin{array}{l}\text { From 40 to 200 microns } \\
\text { (hot-dip galvanized) }\end{array}$ \\
\hline CoatingResistance & - & 1 year & Notlessthan 25 years \\
\hline $\begin{array}{l}\text { Area ratio of open } \\
\text { and closed surfaces } \\
\text { to calculate snow } \\
\text { loads }\end{array}$ & $\mathrm{m}^{2}$ & $40 / 60$ & $20 / 80$ \\
\hline
\end{tabular}

The result of the study and selection of structural elements at the design documentation stage:

- the opportunity to avoid time waste on reconciliation of the material during the construction process;

- use of material with a longer service span;

- reduction of coating repair costs as a result of using durable materials;

- reduction of installation costs as a result of adjustment of technological processes of installation and fastening.

B. The function "Planning at the detailed design documentation stage" and the function "Organizing" provide a positive effect due to the savings in the financial resources of the organization because of a reduction in the need for materials and structures, as well as effective planning for the procurement of the same materials.

In connection with the two-stage implementation of the project for the construction of a transport passage consisting of road and railway bridges, the construction stages were carried out in two stages [20]. However, analysis of project documentation and planning of the supply system revealed identical metal structures used for spans at both stages of construction (Fig. 6 and 7).

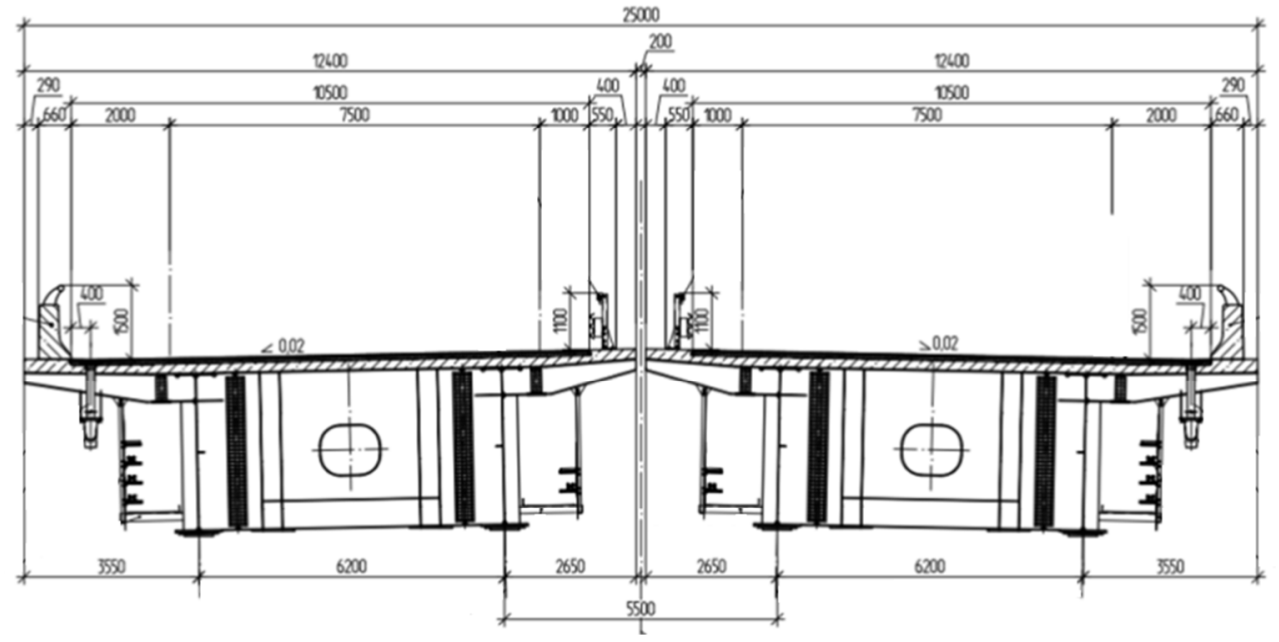

Fig. 6. Cross-section of the road bridge span. 


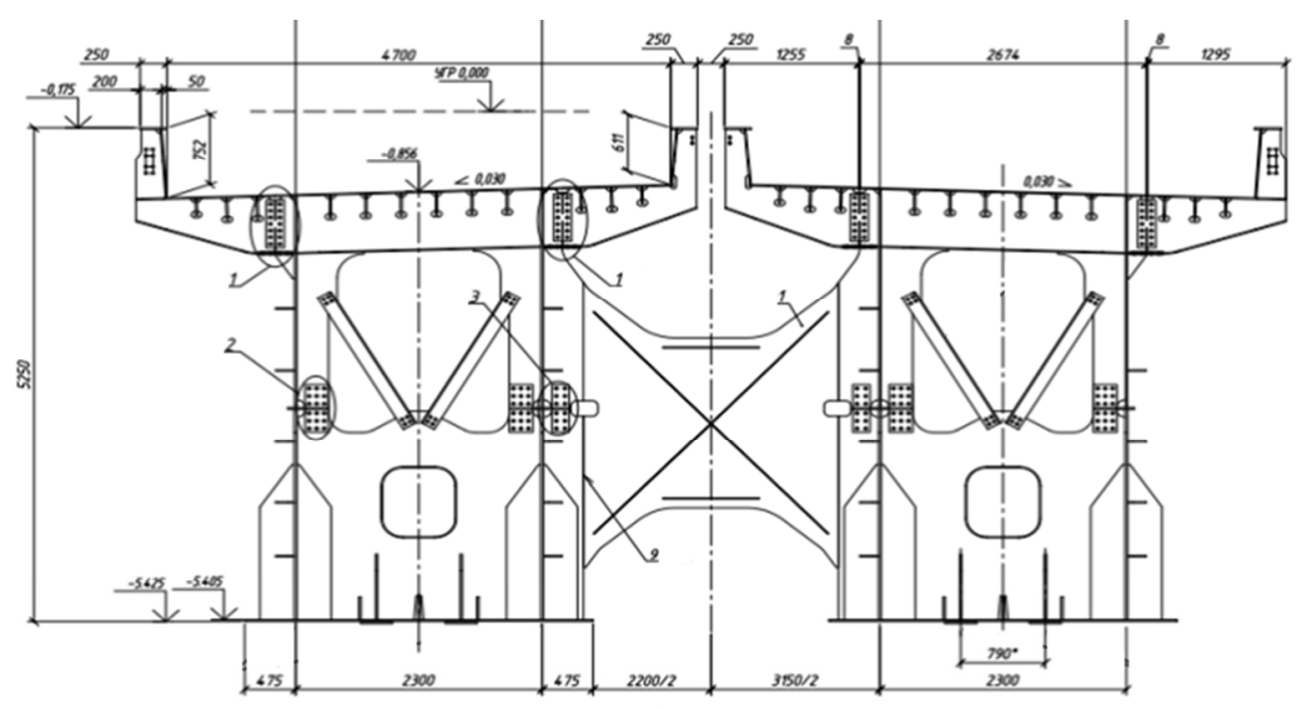

Fig. 7. Cross-section of the railway bridge span.

The considered function in terms of the possibility of saving financial resources is one of the most important for a construction company. The difference between the traditional scheme and the one proposed in the article is the possibility of the supply system of the parent organization to see all the volumes of subsidiaries at the same time, and plan a single supplier and fix the cost for the entire period of construction. In this case, identical metal structures of the road and railway bridges spans were planned for purchase at the stage of analysis of project documentation. An additional advantage is the fact that with fewer suppliers, it is easier to track and control the shipment, its timeliness and the quality of the materials and structures supplied [21,22].

In the proposed logistics scheme at this stage, the functions between the supply system of the parent and subsidiary organizations distributed as follows:

- Subsidiaries supply system:

- the processing of the received working documentation to determine the timing and quantity of materials required for the purchase, create a schedule for the supply of materials in accordance with the developed work schedule;

- execution and filing of an application for the supply of materials in accordance with the developed regulations on centralized procurement (justification of need, delivery time, delivery conditions).

- Parent organization supply system:

- verification of the need for the declared materials (justification, availability of materials in the warehouses of other subsidiaries, terms in accordance with the schedule of work, etc.);

- decision-making on the application (acceptance of the application for centralized placement, rejection of the application due to unfoundedness, transfer of procurement to decentralization).

\section{Discussion}

The proposed mechanism for improving material and technical supply is able to increase the profit of the construction company. The main task of the created department of material and technical supply management of the parent organization is to ensure the integration of 
the processes of placing orders preparation for inventory items into a single whole, the manufacture of semi-finished products, structures and their complete delivery to construction sites in accordance with the schedule of construction and installation works taking into account the stocks residuals available at the enterprise.

The main advantage of such an organization of material and technical supply of construction production is that during the creation and development of management at a construction company all functions and departments of material and technical supply and equipment are concentrated in one place, which was previously dispersed between its individual divisions, departments, and services, which led to a loss of observability and controllability of the supply process.

\section{Conclusions}

In the presented article, the necessity and effectiveness of improving material and technical supply by introducing a mechanism for combining the supply departments of separate divisions into one system are carried out, which allows effective procurement and distribution of inventory between units by including a mechanism for integrating the supply system at the design stage. Transferring the functional of material and technical supply from subsidiaries to the parent leads to a synergistic effect: the result of the activities of a single functional unit far exceeds the sum of the results of the activities of separate units.Planning of material and technical supply at the design stage involves obtaining a number of effects, such as the absence of periods of material reconciliation at the construction stage, the use of modern materials and building structures, and the reduction of financial costs for technological processes.

\section{References}

1. E.B. Tirkolaee, A. Mardani, Z. Dashtian, M. Soltani, G-W. Weber, Journal of Cleaner Production 25020, 119517 (2020)

2. V.A. Akristiniy, E.A. Dikova, Real Estate: Economics 3, 37-45 (2017)

3. V.A. Stolbova, L.I. Pavlova, Real Estate: Economics 2, 76-84 (2015)

4. S. Liu, L.G. Papageorgiou, N. Shah, Computers \& Industrial Engineering 139, 106189 (2020)

5. A.E. Coronado Mondragon, C.E. Coronado Mondragon, P.J. Hogg, N. RodríguezLópez, Computers \& Industrial Engineering 121, 62-72 (2018)

6. H. Wang, Z. Fang, D. Wang, S. Liu, Computers \& Industrial Engineering 140, 106212 (2020)

7. A.M. Mohammed, S.O. Duffuaa, Expert Systems with Applications 140, 112808 (2020)

8. Q. Li, H. Sun, H. Zhang, W. Li, M. Ouyang, Journal of Cleaner Production 25020, 119552 (2020)

9. M. Kheirabadi, B. Naderi, A. Arshadikhamseh, V. Roshanaei, Expert Systems with Applications 13715, 504-516 (2019)

10. C.A. Moreno-Camacho, J.R. Montoya-Torres, A. Jaegler, N. Gondran, Journal of Cleaner Production 23110, 600-618 (2019)

11. J.W. Fowler, S-H. Kim, D.L. Shunk, Decision Support Systems 123, 113071 (2019)

12. S.H. Alavi, A. Jabbarzadeh, Computers \& Industrial Engineering 125, 69-86 (2018) 
13. T.A. Fedeneva, Modern problems of development of fundamental and applied Sciences 1, 57-61 (2016)

14. A. D. Mitrophanov, Kazan economic Bulletin 5(13), 125-130 (2014)

15. V.A. Akristiniy, A.A. Pogorelova, Economy and entrepreneurship 3(104), 1078-1083 (2019)

16. L.A. Valiullina, Siberian economic Bulletin 1, 81-90 (2015)

17. S.V. Miroshnichenko, Building material 11, $42-44$ (2016)

18. T.V. Tolstunova, T.V. Karlova, I.V. Muravev, Vestnik MGTU Stankin 2(20), 98-101 (2012)

19. V.I. Pleshchenko, Management today 4, 230-234 (2013)

20. T.V. Gritsyuk, V.V. Kotilko, Economy. Management. Right 3(60), 22-25 (2015)

21. A.Y. Plotnikov, Finance, money, investment 4(56), 25-28 (2015)

22. P. Starovoit, Transport strategy-XXI century 38, 84-85 (2018) 